\section{Impact of tyloxapol to combat acute phase response in com- parison with betamethasone and flunixin meglumine follow- ing an ovine experimentally induced endotoxemia model}

\author{
Seyed Mohammad Mehdi Heidari, 1

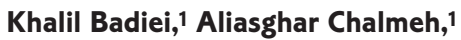 \\ Mehrdad Pourjafar, ${ }^{1}$ \\ Alireza Rahmani Shahraki, ${ }^{1}$ \\ Saeed Nazifi, 1 \\ Mohammad Javad Zamiri2
}

1Department of Clinical Sciences, School of Veterinary Medicine; 2Department of Animal Sciences, College of Agriculture Science, Shiraz University, Shiraz, Iran

\section{Abstract}

Systemic inflammatory responses to circulating lipopolysaccharide lead to high mortality rates in affected animals and thus effective treatments of this situation are crucial. However, despite different endotoxemia therapeutic regimens, the lack of an effective treatment still remains a clinical problem in sheep. Tyloxapol is a potential pro- and anti-inflammatory molecule to treat endotoxemia in farm animals. Hence, the present study was an attempt to clarify the antiendotoxic effects of tyloxapol in comparison with betamethasone and flunixin meglumine in experimentally induced endotoxemia in sheep. Thirty clinically healthy 1-year old Iranian fat-tailed ewes were randomly divided into 6 equal experimental $(n=5)$ groups, comprising Negative and Positive control, Flunixin meglumine, Betamethasone, Tyloxapol 1 and Tyloxapol 2 . Phenol extracted lipopolysaccharide from Escherichia coli serotype 055:B5 was infused at $2 \mu \mathrm{g} / \mathrm{kg}$ intravenously. Ninety min after endotoxemia induction, Flunixin meglumine $(2.2 \mathrm{mg} / \mathrm{kg})$, betamethasone $(1 \mathrm{mg} / \mathrm{kg})$ and tyloxapol (200 and $400 \mathrm{mg} / \mathrm{kg}$ ) were injected to respective groups, over $60 \mathrm{~min}$ along with intravenous fluids. Blood samples were collected from all ewes prior and 1.5, 3, 4.5, 6, 24 and 48 hours after lipopolysaccharide injection and sera and plasmas were separated, subsequently. Haptoglobin, serum amyloid A, tumor necrosis factor-alpha, interferon-gamma, superoxide dismutase and glutathione peroxidase were measured in all samples. Serum concentrations of haptoglobin, serum amyloid A, tumor necrosis factor-alpha, interferongamma in Flunixin meglumine group were found to be lower than other experimental ones after hour 3 . Serum levels of haptoglobin, serum amyloid A, tumor necrosis factor-alpha, interferon-gamma in Tyloxapol groups were significantly lower and higher than Betamethasone and Flunixin meglumine ones, respectively. Superoxide dismutase and glutathione peroxidase activities in Flunixin meglumine group were significantly higher than other experimental groups after administration of drugs. In conclusion, the efficacy of tyloxapol was significantly higher and lower than betamethasone and flunixin meglumine, respectively. Furthermore, tyloxapol doesn't induce its effects by dose dependent manner and its anti- and pro-inflammatory effects at 200 and $400 \mathrm{mg} / \mathrm{kg}$ were statistically similar.

\section{Introduction}

Lipopolysaccharide (LPS), also known as endotoxin, is found in the outer membrane of Gram-negative bacteria, and induces acute phase responses in animals. Endotoxemia is the presence of endotoxins in the blood, which can lead to strong immune response. ${ }^{1}$ The systemic inflammatory response to endotoxemia encompasses the release and proliferation of inflammatory mediators and cells, which are potentially detrimental. 2 The endotoxemia induced acute phase response can be clinically detected by fever, drowsiness, and anorexia. ${ }^{3,4}$

Recent investigations revealed the pathophysiological effects of endotoxemia and maintained the overwhelming production of inflammatory mediators that takes place during the molecular cascade of the systemic inflammatory response syndrome. ${ }^{5}$ However, despite recommending various endotoxemia therapeutic regimens, ${ }^{6-8}$ the lack of an effective treatment still remains a clinical problem and endotoxemia acts as a common cause of high mortality in large animal practice. ${ }^{4}$

Different therapeutic strategies such as administrating the non-steroidal anti-inflammatory drugs (NSAIDs) and corticosteroids are commonly used to combat acute phase responses following endotoxemia. Moreover, tyloxapol has recently been suggested as a proand anti-inflammatory molecule. ${ }^{4}$ Tyloxapol is a nonionic liquid alkyl aryl polyether alcohol, which has a similar chemical structure and action to bile acids as a detergent. Bile acids play a critical role in the body's defense mechanism against infection by binding LPS. ${ }^{9}$ Historically, tyloxapol has been used for the prevention and treatment of tuberculosis in mice. ${ }^{10}$ The pre-treatment with intravenous tyloxapol administration has demonstrated the effectiveness of this detergent to prevent fever, leucopenia and pulmonary hypertension in endotoxin horses.11 Furthermore, tyloxapol has been shown to protect macrophages against activation by endotoxin. ${ }^{12,13}$ However,
Correspondence: Khalil Badiei, Department of Clinical Sciences, School of Veterinary Medicine, Shiraz University, P.0 box: 71345, Shiraz, Iran. Tel: +98.711 .36138700 . Fax: +98.711 .32286940 . E-mail: badiei33@gmail.com

Key words: Endotoxemia; Acute phase response; Treatment; Tyloxapol; Sheep.

Contributions: the authors contributed equally.

Conflict of interest: the authors declare no potential conflict of interest.

Received for publication: 12 October 2015. Revision received: 9 November 2015.

Accepted for publication: 24 November 2015.

This work is licensed under a Creative Commons Attribution NonCommercial 4.0 License (CC BYNC 4.0).

(C) Copyright S.M. Mehdi Heidari et al., 2016 Licensee PAGEPress srl, Italy

Veterinary Science Development 2016; 6:6251 doi:10.4081/vsd.2016.6251

its mechanism of action remains unclear, but may include desensitization of endotoxin receptors. ${ }^{14}$

Antiendotoxic and anti-inflammatory effects of NSAIDs and corticosteroids have been evaluated in sheep, ${ }^{6,7}$ but there are rare investigations on potential therapeutic characteristics of different doses of tyloxapol for treatment of endotoxemia in ovine models. ${ }^{15}$ Regarding the importance of treatment of acute inflammatory conditions such as endotoxemia in farm animals, the present experiment was conducted to evaluate and compare anti-inflammatory effects of tyloxapol at two different doses, flunixin meglumine and betamethasone on acute inflammatory status due to endotoxin of Escherichia coli serotype 055:B5 induced endotoxemia in Iranian fat-tailed sheep based on measurement of serum acute phase proteins, inflammatory cytokines and oxidative stress biomarkers. The aim of the current study was to investigate the potential efficacy of tyloxapol to protect against bolus intravenous endotoxin administration in sheep. The results of the present study, therefore, may reveal the potential effects of tyloxapol on systemic inflammatory responses in small ruminant medicine in comparison with flunixin meglumine and betamethasone.

\section{Materials and Methods}

\section{Animals}

The present experiment was carried out 
after being approved by the Ethics Committee of School of Veterinary Medicine, Shiraz University. Thirty clinically healthy 1 -year old Iranian fat-tailed ewes $(35 \pm 1.5 \mathrm{~kg}$, bodyweight) were randomly selected for the project in April 2014. All animals were maintained in Laboratory Teaching Barn of Agricultural College of Shiraz University, Badjgah region (latitude of $29^{\circ} 32 \mathrm{~N}$ and longitude $52^{\circ} 35 \mathrm{E}$, $1810 \mathrm{~m}$ above sea level), south of Iran. Four weeks before commencing experiments, each sheep received albendazole $(15 \mathrm{mg} / \mathrm{kg}$, orally; Dieverm ${ }^{\circledR 600}$, Razak Pharmaceutical Co, Tehran, Iran) and ivermectin $(0.2 \mathrm{mg} / \mathrm{kg}$, subcutaneously; $\quad$ Erfamectin ${ }^{\circledR} 1 \%$; $\quad$ Erfan Pharmaceutical Co., Tehran, Iran) to control internal and external probable parasites.

All ewes were maintained in open-shed barns with free access to water and shade. The ration included mainly alfalfa hay, corn silage, corn and barley. Subsequently, ewes were randomly assigned into 6 experimental equal $(n=5)$ groups, namely, negative and positive controls (positive control group received LPS and was treated only by intravenous fluid without any drugs and negative control group received only intravenous fluids), Flunixin meglumine, Betamethasone and Tyloxapol (two groups, 200 and $400 \mathrm{mg} / \mathrm{kg}$ ).

\section{Chemicals and drugs}

Phenol extracted LPS from $E$. coli serotype 055:B5 (Sigma-Aldrich ${ }^{\circledR}$; product NO. L2880) was used to induce endotoxemia in ewes at 2 $\mu \mathrm{g} / \mathrm{kg}$ as bolus intravenous administration. During experiment, each sheep (except sheep of negative control group) received only one dose of the LPS and no further administration was allowed. Accordingly, LPS tolerance phenomenon was prevented. 4 This endotoxin was diluted in sterile phosphate-buffered saline and divided into 30 equal doses each containing $70 \mu \mathrm{g}$ endotoxin and stored at $-80^{\circ} \mathrm{C}$ until endotoxemia induction. For all experimental groups (except negative control group), each dose of endotoxin was thawed and infused intravenously as described previously. Flunixin meglumine $\quad\left(M e g a n i x^{\circledR} \quad 5 \%, \quad\right.$ Erfan Pharmaceutical Co., at $2.2 \mathrm{mg} / \mathrm{kg}$ ), betamethasone (Iranhormone Pharmaceutical Co., at 1 $\mathrm{mg} / \mathrm{kg}$ ) and tyloxapol (Triton WR-1330; SigmaAldrich; St. Louis, M0, USA, at 200 and 400 $\mathrm{mg} / \mathrm{kg}$ ) were intravenously injected to respective groups. The intravenous fluid used in the present experiment was dextrose $5 \%$ plus sodium chloride $0.45 \%$ (Shahid Ghazi Pharmaceutical Co., Tabriz, Iran).

\section{Experimental procedures}

\section{Induction and treatment of endotoxemia}

A 16 gauge $5.1 \mathrm{~cm}$ catheter was secured in the left jugular vein and used for blood samplings, and infusion of endotoxin and drugs.
All thirty ewes were evaluated clinically before and 1.5, 3, 4.5, 6, 24 and 48 hours after LPS injection. Clinical parameters were monitored during experiments, including rectal temperature, heart and respiratory rates, cardiac tonicity, mucous membrane color and capillary refill time. In this study, we graded the normal mucous membranes color and cardiac tonicity as 1 and congested mucous membranes and high cardiac tonicity as 2 .

Thawed LPS was diluted in $250 \mathrm{~mL}$ of normal saline and infused intravenously at the rate of $10 \mathrm{ml} / \mathrm{kg} / \mathrm{h}$. Fluid therapy was performed in all experimental groups over 90 min after LPS injection by dextrose $5 \%$ plus sodium chloride $0.45 \%$ at the rate of $20 \mathrm{~mL} / \mathrm{kg} / \mathrm{h}$. Drugs (flunixin meglumine, betamethasone and tyloxapol) were used, along with fluid therapy at 90 min after LPS injection over $60 \mathrm{~min}$. Tyloxapol was diluted in used fluids over 60 min before administration. Positive control group received LPS and was treated only by intravenous fluid without any drugs, whereas negative control group received intravenous fluids only.

\section{Blood sampling and biochemical assays}

Blood samples were collected from all ewes through the fixed catheter prior and 1.5, 3, 4.5, 6,24 and 48 hours after LPS injection in plain and EDTA coated tubes. Immediately after collections, sera and plasmas were separated by centrifugation (for $10 \mathrm{~min}$ at $3000 \times \mathrm{g}$ ) and stored at $-22^{\circ} \mathrm{C}$ until assayed.
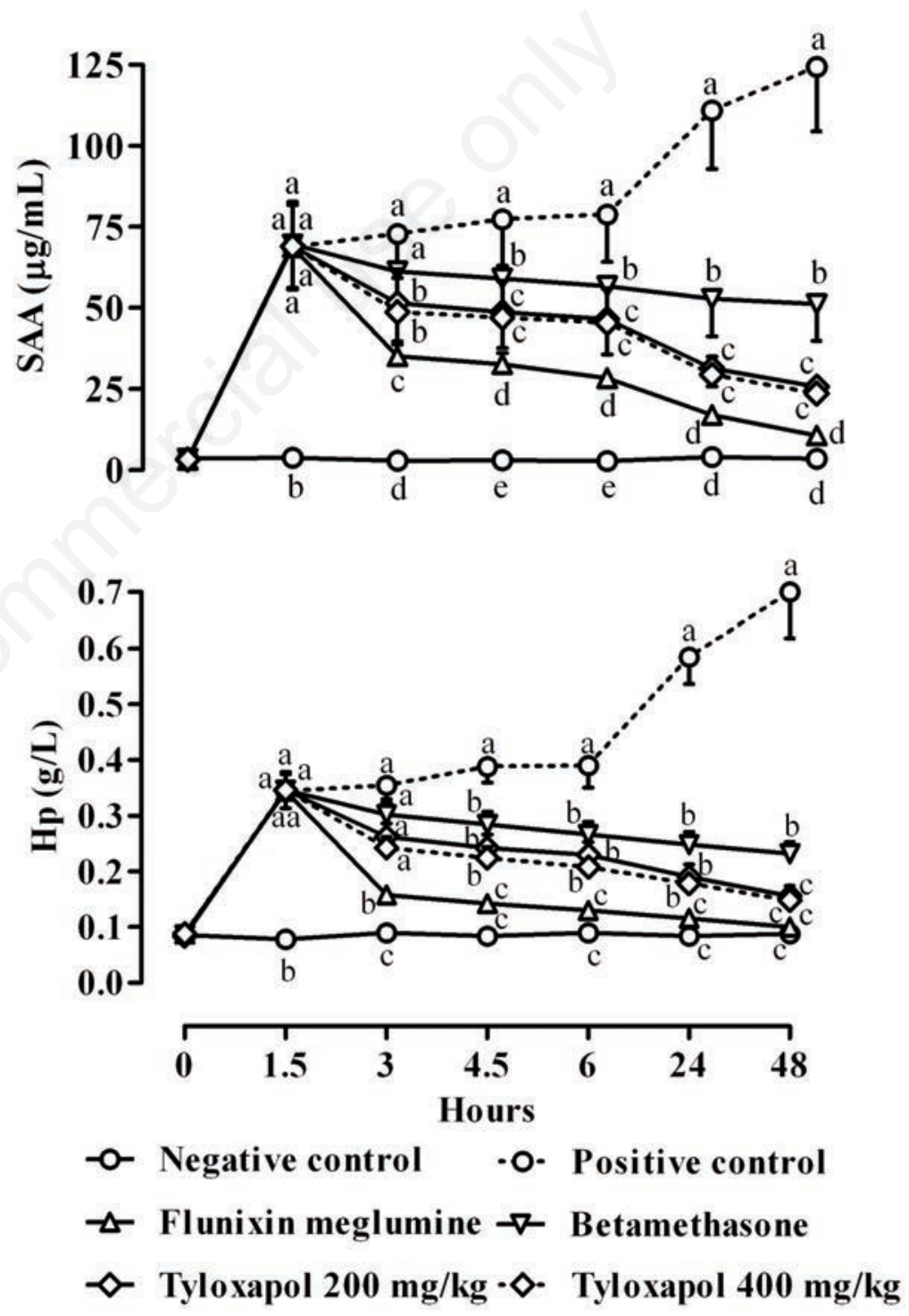

Figure 1. Concentrations of serum amyloid $A$ and haptoglobin in different treatments following endotoxin infusion in Iranian fat-tailed sheep. Data are presented as mean \pm standard deviation. Different letters indicates significant differences among experimental groups at similar hours. 
Haptoglobin (Hp) was measured according to prevention of peroxidase activity of hemoglobin, which is directly proportional to the amount of Hp (Tridelta Development Plc, Wicklow, Ireland). Serum amyloid A (SAA) was measured by a solid phase sandwich ELISA (Tridelta Development Plc, Wicklow, Ireland). Tumor necrosis factor-alpha (TNF- ) and interferon-gamma (IFN- $\gamma$ ) were measured by a solid phase sandwich ELISA (AbC 606 and 607, respectively; Votre fournisseur AbCys S.A. Paris, France). The superoxide dismutase (SOD) activity was measured by a modified method of iodophenyl nitrophenol phenyltetrazolium chloride (Ransod Kit, Randox Com, UK). ${ }^{16}$ The glutathione peroxidase (GPx) activity was measured by the method of Paglia and Valentine (Ransel kit, Randox Com, UK). ${ }^{17}$

\section{Statistical analyses}

Data were expressed as mean \pm standard deviation (SD). Statistical analysis was performed using one-way ANOVA with LSD post hoc test to compare mean concentrations of different serological factors and quantitative clinical parameters within similar hours between different experimental groups. Repeated measures ANOVA were used to detect significant changing patterns of serological factors during all experiments. The data of qualitative clinical parameters were presented as median (min-max) and KruskalWallis test was used for comparison of these parameters between all groups. Paired samples $\mathrm{t}$-test was used to determine differences between two different times in each experimental group using SPSS software (SPSS for Windows, version 11.5, SPSS Inc., Chicago, Illinois). The level of significance was set at $\mathrm{P}<0.05$.

\section{Results}

Serum concentrations of SAA and Hp at different time intervals for experimental groups have been presented in Figure 1. The reference ranges of SAA and Hp were $3.6 \pm 0.15$ $\mu \mathrm{g} / \mathrm{mL}$ and $0.08 \pm 0.01 \mathrm{~g} / \mathrm{L}$, respectively. SAA and Hp elevated rapidly after endotoxemia induction in all experimental groups, except negative control group. There was no significant changing pattern in negative control group. These rapid elevations were diverse between the hour zero and first time after endotoxin infusion $(\mathrm{P}<0.05)$. Serum concentrations of $\mathrm{SAA}$ and $\mathrm{Hp}$ in Flunixin meglumine group were lower than other experimental groups after hour 3 (Figure 1). Serum levels of Hp and SAA in tyloxapol groups were significantly lower than betamethasone one.

Serum concentrations of TNF- $\alpha$ and IFN- $\gamma$ in different time intervals in each experimen- tal group are presented in Figure 2. The base line values of TNF- $\alpha$ and IFN- $\gamma$ were $0.36 \pm 0.01$ and $16.05 \pm 0.86 \mathrm{pg} / \mathrm{dL}$, respectively. Rapid elevation of serum TNF- $\alpha$ and IFN- $\gamma$ was detected after endotoxemia induction in all experimental groups, except for negative control one (Figure 2). There were significant differences between TNF- $\alpha$ at first time after endotoxin infusion and its base line levels at zero hour $(\mathrm{P}<0.05)$. The same pattern was also observed for IFN- $\gamma$. The lowest and highest concentrations of both TNF- $\alpha$ and IFN- $\gamma$ were detected in flunixixn meglumine and betamethasone groups, respectively. There were no significant differences between tyloxapol groups.

Base line levels of SOD and GPx were
$1323.58 \pm 42.67$ and $228.08 \pm 10.75 \mathrm{U} / \mathrm{g} \mathrm{Hb}$, respectively. Serum activities of SOD and GPX at first time after endotoxemia induction were significantly lower than base line levels at zero hour, in all experimental groups $(\mathrm{P}<0.05$, Figure 3), except for negative control one. SOD and GPx activities in flunixin meglumine group were significantly higher than other experimental groups after administration of drugs.

The results of monitored clinical parameter have been presented in Tables 1-5. Rectal temperature in all received LPS groups increased significantly after endotoxin infusion. The rectal temperature of flunixin meglumine group at hours 4.5 and 6 was significantly lower than
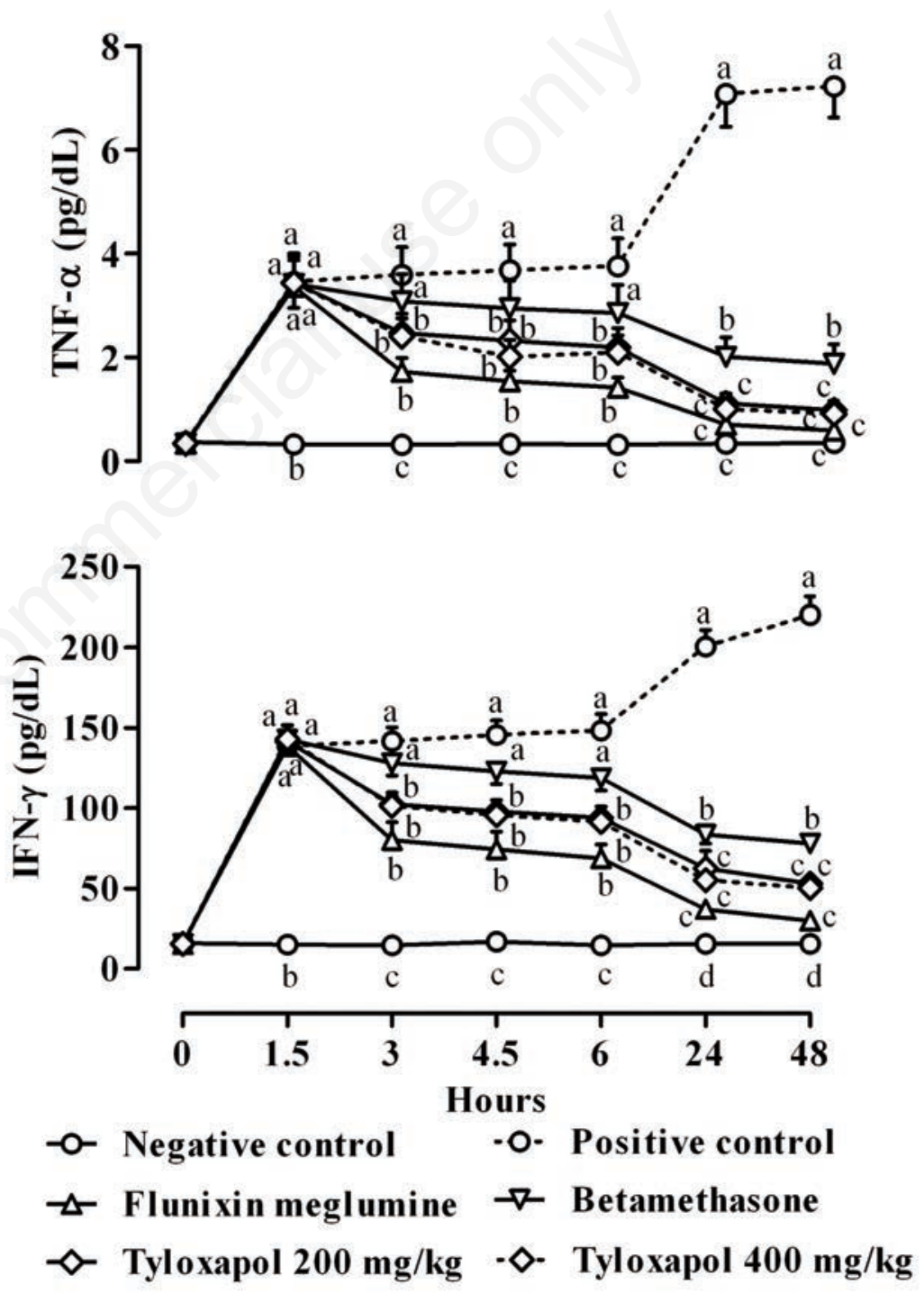

Figure 2. Effect of tyloxapol, betamethasone and flunixin meglumine on tumor necrosis factor-alpha and interferon-gamma serum concentrations at various times following endotoxemia and its treatment in Iranian fat-tailed sheep. Data are presented as mean \pm standard deviation. Different letters indicates significant differences among experimental groups at similar hours. 
other endotoxin received groups (Table 1; $\mathrm{P}<0.05$ ). Heart rate of all experimental groups increased significantly after endotoxin infusion. The rate of heartbeat in flunixin meglumine group at hour 4.5 was lower than other LPS received groups (Table $2 ; \mathrm{P}<0.05$ ). The increasing pattern of respiratory rate was detected after intravenous LPS infusion. The respiratory rate of Flunixin meglumine group was significantly lower than other LPS received groups at hours 4.5 and 6 (Table 3; $\mathrm{P}<0.05)$. Capillary refill time increased significantly after endotoxin infusion and this parameter was significantly higher than its value in negative control group. Capillary refill time in flunixin meglumine group was lower than other groups, particularly after administrations of drugs (Table $4 ; \mathrm{P}<0.05$ ). Cardiac tonicity increased and mucus membrane was congested after LPS infusion in all endotoxin received groups. These parameters in betamethasone group at hour 6 were significantly higher than other drug treated groups (Table 5; $\mathrm{P}<0.05$ ).

All sheep were considered permanent survivors, alive and healthy after all experiments.

\section{Discussion and Conclusions}

Endotoxemia is characterized by a mortality rate higher than 50\%. ${ }^{4}$ Endotoxin and its interactions with the immune system is believed to be one of the major factors in the complex set of pathophysiological events leading to septic injuries. ${ }^{18}$ Hence, treatment of the acute phase response to circulating endotoxin and researches on the new therapeutic approaches of endotoxemia are necessary. Tyloxapol has been introduced as a potential anti-inflammatory drug to treat endotoxemia in farm animals, ${ }^{4}$ but information regarding its antiendotoxic effects in sheep is rare. 15 Hence, the present experiment was designed to evaluate the anti-inflammatory effects of tyloxapol in comparison with betamethasone and flunixin meglumine in an ovine endotoxemia model.

Changing the acute phase proteins (APPs), as the biomarkers of inflammatory processes, due to various inflammatory conditions have been studied in animals. ${ }^{19}$ The sensitivity of evaluation of APPs in diagnosis of the disease is more than hematological and clinical tests. However, APPs have been increased during the development of systemic inflammatory response syndrome and decreased in the recovery stages of inflammatory conditions. ${ }^{20}$ Acute phase response in experimental endotoxemia and its comparative treatment with dexamethasone and flunixin meglumine in sheep has been studied, previously, ${ }^{5}$ but information regarding the treatment of experimentally induced endotoxemia by tyloxapol in sheep has been rare.

SAA and Hp as well as other APPs have been proposed as markers of stress in animals. ${ }^{21}$ Determination and evaluation of SAA showed that this APP could be a valuable factor in the diagnosis of infections. ${ }^{22}$ In ruminants, the level of circulating $\mathrm{Hp}$ is negligible in normal animals but increases over 100 -fold with immune stimulation. 16 Furthermore, $\mathrm{Hp}$ is a clinically useful parameter for the evaluation of the occurrence and severity of inflammatory diseases in sheep. ${ }^{23}$

The results of the present experiment demonstrated that SAA elevated rapidly after endotoxemia induction in all endotoxin received groups, $(\mathrm{P}<0.05$; Figure 1). Elevated serum concentrations of SAA are found following inflammation. ${ }^{24}$ In the present experiment, rapid elevation in serum concentrations of $\mathrm{Hp}$ in all ewes was observed following endotoxin infusion, $(\mathrm{P}<0.05$; Figure 1$)$. The results of the present study showed that intravenous infusion of flunixin meglumine at $2.2 \mathrm{mg} / \mathrm{kg}$ was more effective than other drugs in decreasing the serum concentrations of both SAA and Hp at different hours, $(\mathrm{P}<0.05$; Figure 1). Serum concentrations of these APPs in Tyloxapol groups were significantly higher and lower than flunixin meglumine and betamethasone groups, respectively. There were no significant differences between tyloxapol groups in decreasing the concentrations of SAA and Hp

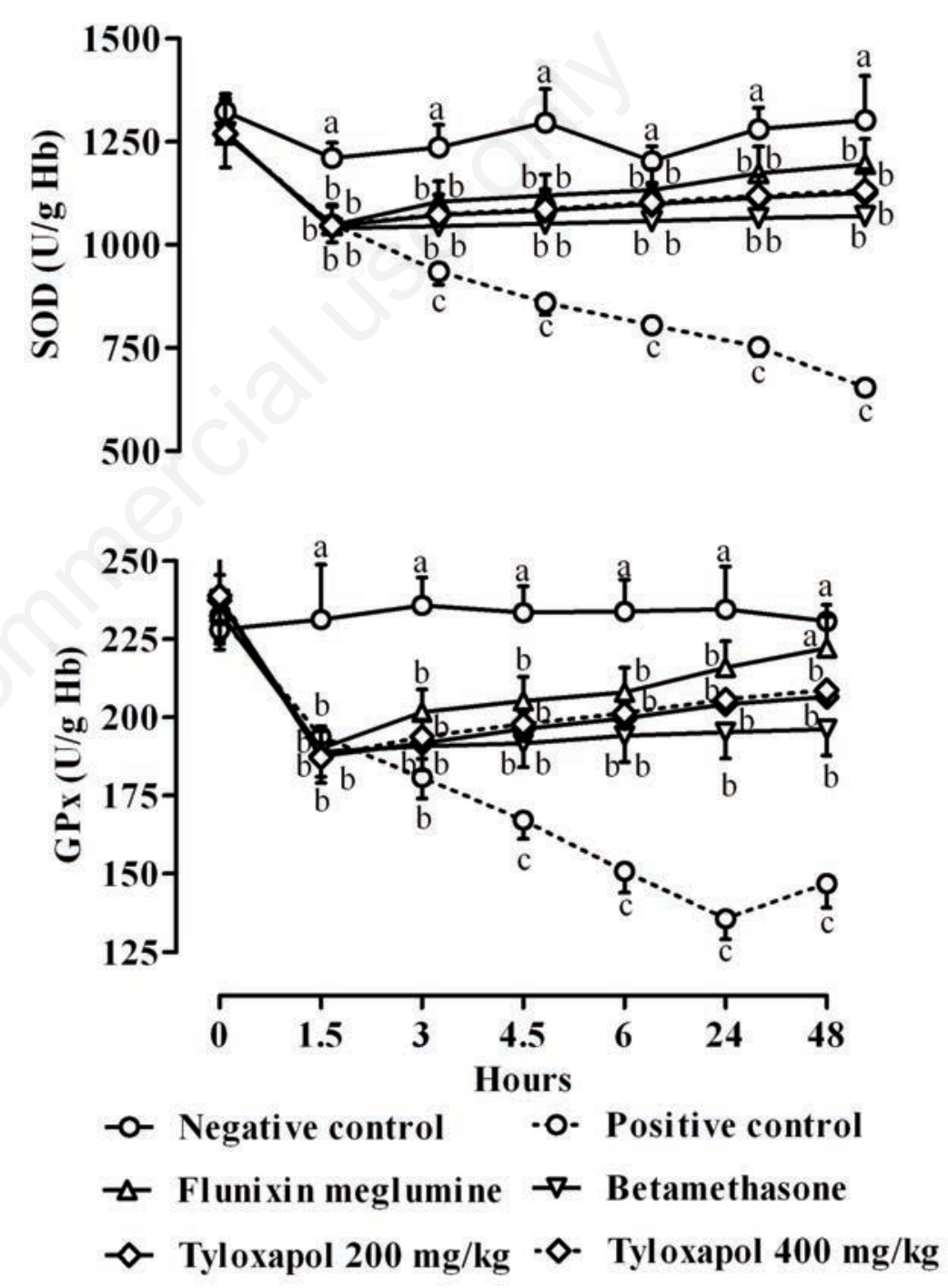

Figure 3. Effect of tyloxapol, betamethasone and flunixin meglumine on serum concentrations of super oxide dismutase and glutathione peroxidase during endotoxemia and subsequent treatment in Iranian fat-tailed sheep. Data are presented as mean \pm standard deviation and different letters indicates significant differences among experimental groups at similar hours. 
( $P>0.05$; Figure 1).

Detergents such as tyloxapol are known to be nonspecific blockers of many receptormediated processes; they are also enzyme inhibitors. Tyloxapol is originally used as a mucolytic agent, it was soon discovered that it caused profound hyperlipemia when given parentally because it blocks endothelial surface lipoprotein lipase. ${ }^{25}$ Staub and colleagues $^{15}$ demonstrated that nonionic detergents block endocytosis of LPS by endothelial cells in culture. They used 200 and $300 \mathrm{mg} / \mathrm{kg}$ of tyloxapol intravenously in endotoxic sheep and mentioned that both doses were completely safe, no sheep became ill or died after receiving tyloxapol. We used 200 and 400 $\mathrm{mg} / \mathrm{kg}$ of tyloxapol in this study and found no significant differences between two different doses in reducing acute phase protein concen- trations.

TNF- $\alpha$ is a cytokine involved in systemic inflammation and a member of a group of cytokines that stimulate the acute phase response. Large amounts of TNF- $\alpha$ are released in response to endotoxins. On the liver, TNF- $\alpha$ stimulates the acute phase response, leading to an increase in APPs. ${ }^{26}$ Significant $(\mathrm{P}<0.05)$ and rapid elevation of serum TNF- $\alpha$ was observed before commencing intravenous fluid therapy in all experimental groups. In the present experimental endotoxemia induction, more marked and significant depression of TNF- $\alpha$ was observed in flunixin meglumine group than other LPS received ones at different hours after commencing fluid therapy $(\mathrm{P}<0.05$; Figure 2$)$.

Staub and colleagues ${ }^{15}$ revealed that the increase in pulmonary vascular pressure and microvascular leakiness, the febrile response, and the inflammatory response (leukopenia and increased plasma TNF- $\alpha$ concentration) caused by endotoxin were markedly attenuated by tyloxapol. They mentioned that other important advantages of tyloxapol over macrophage depletion were blocking some of the systemic responses. In the same way, other researchers also expressed that the dramatic effects of tyloxapol in reducing the endotoxin-induced rise in circulating TNF- $\alpha$ are similar to the effects of tyloxapol in reducing the other physiological changes after endotoxin administration. 15

IFN- $\gamma$ is a cytokine that is critical for innate and adaptive immunity against viral and intracellular bacterial infections. Endotoxin activates macrophage microbicidal effector functions and production of pro-inflammatory

Table 1. Effect of tyloxapol, betamethasone and flunixin meglumine on rectal temperature $\left({ }^{\circ} \mathrm{C}\right.$, mean $\left.\pm \mathrm{SD}\right)$ at different times following induction and treatment of endotoxemia in Iranian fat-tailed sheep.

\begin{tabular}{|c|c|c|c|c|c|c|c|}
\hline \multirow[t]{2}{*}{ Groups } & \multicolumn{7}{|c|}{ Times (h) } \\
\hline & 0 & 1.5 & 3 & 4.5 & 6 & 24 & 48 \\
\hline Negative control & $38.8 \pm 0.1$ & $38.8 \pm 0.1^{\mathrm{a}}$ & $38.9 \pm 0.2^{\mathrm{a}}$ & $38.9 \pm 0.1^{\mathrm{a}}$ & $38.8 \pm 0.1^{\mathrm{a}}$ & $38.9 \pm 0.2$ & $38.8 \pm 0.2$ \\
\hline Positive control & $38.8 \pm 0.2$ & $39.1 \pm 0.1^{\mathrm{b}}$ & $39.1 \pm 0.1^{\mathrm{b}}$ & $39.4 \pm 0.1^{b}$ & $39.5 \pm 0.2^{b}$ & $39.0 \pm 0.1$ & $38.9 \pm 0.1$ \\
\hline Flunixin meglumine & $39.0 \pm 0.1$ & $39.1 \pm 0.2^{b}$ & $39.3 \pm 0.1^{\mathrm{b}}$ & $38.9 \pm 0.1^{\mathrm{a}}$ & $38.9 \pm 0.1^{\mathrm{a}}$ & $38.9 \pm 0.2$ & $39.0 \pm 0.1$ \\
\hline Betamethasone & $39.1 \pm 0.2$ & $39.1 \pm 0.1^{b}$ & $39.3 \pm 0.1 \mathrm{~b}$ & $39.2 \pm 0.2^{b}$ & $39.1 \pm 0.1 \mathrm{~b}$ & $38.9 \pm 0.1$ & $38.8 \pm 0.1$ \\
\hline Tyloxapol 200 mg/kg & $39.0 \pm 0.2$ & $39.2 \pm 0.1^{b}$ & $39.3 \pm 0.1 \mathrm{~b}$ & $39.2 \pm 0.2^{b}$ & $39.2 \pm 0.1 \mathrm{~b}$ & $38.8 \pm 0.1$ & $38.9 \pm 0.2$ \\
\hline Tyloxapol 400 mg/kg & $38.9 \pm 0.1$ & $39.0 \pm 0.1^{b}$ & $39.2 \pm 0.2^{b}$ & $39.2 \pm 0.1^{b}$ & $39.1 \pm 0.2^{b}$ & $39.0 \pm 0.1$ & $38.9 \pm 0.2$ \\
\hline
\end{tabular}

Different letters indicated significant differences among experimental groups at similar hours $(\mathrm{P}<0.05)$.

Table 2. Heart rate changes (beats/min, mean $\pm \mathrm{SD}$ ) during induction and treatment of endotoxemia in Iranian fat-tailed sheep.

\begin{tabular}{|c|c|c|c|c|c|c|c|}
\hline \multirow[t]{2}{*}{ Groups } & \multicolumn{7}{|c|}{ Times (h) } \\
\hline & 0 & 1.5 & 3 & 4.5 & 6 & 24 & 48 \\
\hline Negative control & $85.1 \pm 2.7$ & $88.2 \pm 4.1^{\mathrm{a}}$ & $87.0 \pm 5.4^{a}$ & $92.1 \pm 3.4^{\mathrm{a}}$ & $87.1 \pm 3.2^{\mathrm{a}}$ & $94.1 \pm 5.4$ & $85.1 \pm 8.7$ \\
\hline Positive control & $89.4 \pm 3.4$ & $99.3 \pm 2.5^{b}$ & $109.1 \pm 5.1^{b}$ & $115.3 \pm 4.8^{b}$ & $121.3 \pm 4.8^{b}$ & $92.2 \pm 4.6$ & $90.2 \pm 5.6$ \\
\hline Flunixin meglumine & $92.3 \pm 3.5$ & $101.4 \pm 3.7 \mathrm{~b}$ & $110.2 \pm 2.8^{b}$ & $98.2 \pm 4.6^{\mathrm{a}}$ & $94.4 \pm 5.6 \mathrm{c}$ & $88.3 \pm 3.4$ & $89.8 \pm 4.5$ \\
\hline Betamethasone & $88.0 \pm 4.8$ & $98.4 \pm 5.6^{b}$ & $108.3 \pm 5.7 \mathrm{~b}$ & $105.3 \pm 5.7 \mathrm{~b}$ & $99.2 \pm 4.9 \mathrm{c}$ & $85.2 \pm 5.9$ & $87.9 \pm 6.4$ \\
\hline Tyloxapol 200 mg/kg & $87.7 \pm 5.2$ & $95.6 \pm 4.9^{b}$ & $101.1 \pm 4.6^{b}$ & $104.4 \pm 7.1^{\mathrm{b}}$ & $98.3 \pm 5.6^{\mathrm{c}}$ & $87.1 \pm 4.6$ & $86.7 \pm 6.4$ \\
\hline Tyloxapol 400 mg/kg & $85.2 \pm 2.1$ & $93.7 \pm 5.6^{\mathrm{b}}$ & $99.7 \pm 4.9 \mathrm{~b}$ & $102.5 \pm 6.3^{b}$ & $101.7 \pm 4.8 \mathrm{c}$ & $89.8 \pm 3.5$ & $87.5 \pm 3.5$ \\
\hline
\end{tabular}

Different letters indicated significant differences among experimental groups at similar hours $(\mathrm{P}<0.05)$

Table 3. Changes of respiratory rate (times/min, mean \pm SD) after tyloxapol, betamethasone and flunixin meglumine administration at different times following induction and treatment of endotoxemia in Iranian fat-tailed sheep.

\begin{tabular}{|c|c|c|c|c|c|c|c|}
\hline \multirow{2}{*}{ Groups } & \multicolumn{7}{|c|}{ Times (h) } \\
\hline & 0 & 1.5 & 3 & 4.5 & 6 & 24 & 48 \\
\hline Negative control & $25.2 \pm 2.5$ & $26.3 \pm 3.6^{\mathrm{a}}$ & $27.8 \pm 2.9 \mathrm{a}$ & $23.9 \pm 2.9 \mathrm{a}$ & $24.8 \pm 3.4 \mathrm{a}$ & $25.6 \pm 3.8$ & $24.9 \pm 3.4$ \\
\hline Positive control & $26.4 \pm 3.4$ & $42.5 \pm 2.5^{b}$ & $48.9 \pm 2.3^{b}$ & $51.3 \pm 2.8^{b}$ & $59.6 \pm 3.7^{\mathrm{b}}$ & $27.1 \pm 2.6$ & $26.9 \pm 4.8$ \\
\hline Flunixin meglumine & $25.4 \pm 2.6$ & $40.1 \pm 4.2^{b}$ & $45.6 \pm 3.5^{b}$ & $37.9 \pm 3.4 \mathrm{c}$ & $32.1 \pm 2.9 c$ & $26.7 \pm 4.6$ & $25.4 \pm 2.9$ \\
\hline Betamethasone & $23.4 \pm 3.4$ & $41.2 \pm 1.8^{b}$ & $47.9 \pm 4.2^{b}$ & $42.9 \pm 4.6^{\mathrm{d}}$ & $40.8 \pm 4.6^{\mathrm{d}}$ & $24.7 \pm 2.8$ & $23.9 \pm 3.4$ \\
\hline Tyloxapol $200 \mathrm{mg} / \mathrm{kg}$ & $29.7 \pm 3.5$ & $39.9 \pm 2.6^{b}$ & $46.7 \pm 3.1^{b}$ & $41.9 \pm 2.8 \mathrm{~d}$ & $37.1 \pm 5.5^{\mathrm{d}}$ & $28.7 \pm 3.7$ & $26.5 \pm 2.6$ \\
\hline Tyloxapol 400 mg/kg & $27.6 \pm 2.8$ & $40.1 \pm 3.4 \mathrm{~b}$ & $45.6 \pm 2.9 \mathrm{~b}$ & $40.8 \pm 3.4^{\mathrm{d}}$ & $36.4 \pm 3.7 \mathrm{~d}$ & $25.9 \pm 2.9$ & $26.4 \pm 4.1$ \\
\hline
\end{tabular}

Different letters indicated significant differences among experimental groups at similar hours $(\mathrm{P}<0.05)$. 
cytokines, such as IFN- $\gamma .{ }^{27}$ The results of the IFN- $\gamma$ assay showed that serum concentration of this inflammatory cytokine was significantly lower in flunixin meglumine group than other experimental groups after treatments $(\mathrm{P}<0.05$; Figure 2). Serum concentrations of TNF- $\alpha$ and IFN- $\gamma$ in tyloxapol groups were significantly higher and lower than flunixin meglumine and betamethasone groups, respectively. There were no significant differences between tyloxapol groups in decreasing the concentrations of these inflammatory cytokines $(\mathrm{P}>0.05$; Figure 2).

The pathology of endotoxemia is probably jointly mediated by multiple cytokines released during sepsis. Both exogenously administered and endogenously produced IFN- $\gamma$ demonstrably contributes to endotoxic mortality as well. ${ }^{26}$ The ability of IFN- $\gamma$ to increase macrophage TNF- $\alpha$ production by both transcriptional and translational mechanisms has been well described. ${ }^{28}$

At suitable doses, tyloxapol stabilizes biological membranes and modulates membranerelated processes in cells. ${ }^{25}$ Tyloxapol may affect the conformation of membrane receptors for LPS (CD14) or adhesion receptors (such as CD11/CD18), thus acting as antagonists. Tyloxapol inhibits activation of alveolar macrophages by LPS and blocks the release of TNF- $\alpha$ and other cytokines such as IFN- $\gamma$. The mechanism of tyloxapol action as a blocker of receptor ligand interaction appears to be a hydrophobic association with receptor nonpolar groups. ${ }^{15}$

Ghio and colleagues ${ }^{13}$ demonstrated that tyloxapol inhibits the activation of the nuclear factor kappa B, reduces resting secretion of interleukin (IL)-8 and inhibits lipopolysaccharide-stimulated release of TNF-, IL-1, IL-6, granulocyte-macrophage colony stimulating factor and the eicosanoids thromboxane A2 and leukotriene B4 in cultured human monocytes. Therefore it may be stated that one of the direct mechanisms of tyloxapol action is blockade of activation of immune cells by blockade of LPS binding to LPS receptors.

SOD is the key antioxidant enzyme since superoxide is one of the main reactive oxygen species in the cell. SOD is responsible for the quenching of superoxide radicals which are released during the chemical reactions of the various metabolic pathways. ${ }^{29}$ In the present experiment, a decreasing pattern of serum SOD activities was seen after endotoxemia induction and this pattern in positive control group continued up to hour 48 (Figure 3 ). In flunixin meglumine group, levels of SOD were increased after treatment and these levels were near to base line levels at hour 48.

GPx is an endogenous antioxidant, which protects cells from free radicals. ${ }^{30}$ The activity of GPx is used as an indicator for oxidative stress. ${ }^{31}$ Its activity increases in affected ani- mals. According to our findings, serum GPx activity was depressed after intravenous LPS infusion and these depressions were continued in positive control group until hour 48 (Figure 3). In Flunixin meglumine group, levels of GPx activity increased after treatment and these levels were near to base line levels at $48^{\text {th }}$ hour. Our results showed that intravenous infusion of flunixin meglumine at $2.2 \mathrm{mg} / \mathrm{kg}$ was more effective than other drugs in changing the oxidative stress at different hours, $(\mathrm{P}<0.05$; Figure 3$)$. Serum activities of SOD and GPx in tyloxapol groups were significantly higher and lower than betamethasone and flunixin meglumine groups, respectively. There were no significant differences between tyloxapol groups in changing pattern of SOD and GPx (P>0.05; Figure 3$)$.

The results of Serikov and colleagues 14 revealed that tyloxapol attenuates endotoxininduced shock and septic death in vivo, which was associated with blockade of endotoxin binding to cell receptors in vitro. They therefore concluded that the blockade of endotoxin binding is the primary mechanism of Tyloxapol activity in vivo. The protective effect of tyloxapol was also highlighted in the survival of rats with experimentally induced peritonitis and sepsis. Serikov and colleagues ${ }^{14}$ also revealed that tyloxapol directly blocks binding of endotoxin to macrophages. It may be stated that combating the acute phase response by

Table 4. Comparative effect of tyloxapol, betamethasone and flunixin meglumine on capillary refill time (sec, mean \pm SD) at different times subsequent to induction and treatment of endotoxemia in Iranian fat-tailed sheep.

\begin{tabular}{|c|c|c|c|c|c|c|c|}
\hline \multirow[t]{2}{*}{ Groups } & \multicolumn{7}{|c|}{ Times (h) } \\
\hline & 0 & 1.5 & 3 & 4.5 & 6 & 24 & 48 \\
\hline Negative control & $2.1 \pm 0.1$ & $2.1 \pm 0.1^{\mathrm{a}}$ & $2.0 \pm 0.1^{\mathrm{a}}$ & $2.1 \pm 0.1^{\mathrm{a}}$ & $2.0 \pm 0.1^{\mathrm{a}}$ & $2.0 \pm 0.1$ & $2.1 \pm 0.1$ \\
\hline Positive control & $2.0 \pm 0.1$ & $2.4 \pm 0.2^{b}$ & $2.9 \pm 0.2^{b}$ & $3.2 \pm 0.2^{\mathrm{b}}$ & $3.2 \pm 0.2^{\mathrm{b}}$ & $2.1 \pm 0.1$ & $2.0 \pm 0.1$ \\
\hline Flunixin meglumine & $2.0 \pm 0.1$ & $2.3 \pm 0.1^{\mathrm{b}}$ & $2.8 \pm 0.2^{b}$ & $2.4 \pm 0.3 \mathrm{c}$ & $2.2 \pm 0.3 \mathrm{c}$ & $2.0 \pm 0.1$ & $2.2 \pm 0.1$ \\
\hline Betamethasone & $2.1 \pm 0.1$ & $2.4 \pm 0.1^{b}$ & $3.0 \pm 0.3^{b}$ & $2.8 \pm 0.2^{\mathrm{d}}$ & $2.6 \pm 0.1^{\mathrm{d}}$ & $2.1 \pm 0.1$ & $2.1 \pm 0.1$ \\
\hline Tyloxapol 200 mg/kg & $2.0 \pm 0.1$ & $2.4 \pm 0.1^{b}$ & $2.9 \pm 0.2^{b}$ & $2.7 \pm 0.1 \mathrm{~d}$ & $2.5 \pm 0.1^{\mathrm{d}}$ & $2.1 \pm 0.1$ & $2.0 \pm 0.1$ \\
\hline Tyloxapol 400 mg/kg & $2.1 \pm 0.1$ & $2.3 \pm 0.2^{b}$ & $3.0 \pm 0.1^{\mathrm{b}}$ & $2.8 \pm 0.2^{\mathrm{d}}$ & $2.5 \pm 0.2 \mathrm{~d}$ & $2.1 \pm 0.1$ & $2.0 \pm 0.1$ \\
\hline
\end{tabular}

Different letters indicated significant differences among experimental groups at similar hours $(\mathrm{P}<0.05)$.

Table 5. Effect of tyloxapol, betamethasone and flunixin meglumine on cardiac tonicity and mucus membrane color at different times following induction and treatment of endotoxemia in Iranian fat-tailed sheep.

\begin{tabular}{|c|c|c|c|c|c|c|c|}
\hline \multirow[t]{2}{*}{ Groups } & \multicolumn{7}{|c|}{ Times (h) } \\
\hline & 0 & 1.5 & 3 & 4.5 & 6 & 24 & 48 \\
\hline Negative control & $1(1-1)$ & $1(1-1)^{\mathrm{a}}$ & $1(1-1)^{\mathrm{a}}$ & $1(1-1)^{\mathrm{a}}$ & $1(1-1)^{\mathrm{a}}$ & $1(1-1)$ & $1(1-1)$ \\
\hline Positive control & $1(1-1)$ & $2(1-2)^{b}$ & $2(1-2)^{b}$ & $2(1-2)^{b}$ & $2(1-2)^{b}$ & $1(1-1)$ & $1(1-1)$ \\
\hline Flunixin meglumine & $1(1-1)$ & $2(1-2)^{b}$ & $2(1-2)^{b}$ & $2(1-2)^{b}$ & $1(1-1)^{\mathrm{a}}$ & $1(1-1)$ & $1(1-1)$ \\
\hline Betamethasone & $1(1-1)$ & $2(1-2)^{b}$ & $2(1-2)^{b}$ & $2(1-2)^{b}$ & $2(1-2)^{b}$ & $1(1-1)$ & $1(1-1)$ \\
\hline Tyloxapol 200 mg/kg & $1(1-1)$ & $2(1-2)^{b}$ & $2(1-2)^{b}$ & $2(1-2)^{b}$ & $1(1-1)^{\mathrm{a}}$ & $1(1-1)$ & $1(1-1)$ \\
\hline Tyloxapol 400 mg/kg & $1(1-1)$ & $2(1-2)^{b}$ & $2(1-2)^{b}$ & $2(1-2)^{b}$ & $1(1-1)^{\mathrm{a}}$ & $1(1-1)$ & $1(1-1)$ \\
\hline
\end{tabular}

Data expressed as median (min-max). The grade of normal cardiac tonicity and mucus membrane color considered as 1 , and high cardiac tonicity and congested mucous membrane graded as 2. Different letters indicated significant differences among experimental groups at similar hours $(\mathrm{P}<0.05)$. 
Tyloxapol affects the consumptive patterns of SOD and GPx. Hence, Tyloxapol can affect against oxidative stress following endotoxemia.

In conclusion, the results of the present experimental study showed that Tyloxapol acts as an anti-inflammatory mediator by decreasing pro-inflammatory cytokines, pro-inflammatory hepatic APPs and modulating oxidative enzymes activity after $E$. coli serotype 055:B5 endotoxemia induction in the Iranian fattailed sheep. Furthermore, its efficacy was significantly higher and lower than betamethasone and flunixin meglumine, respectively. Based on our findings, tyloxapol doesn't induce its effects by dose dependent manner and the anti- and pro-inflammatory effects of this detergent at 200 and $400 \mathrm{mg} / \mathrm{kg}$ were statistically similar. Finally, it may be suggested that tyloxapol can be used as an antiendotoxic drug against the acute inflammatory conditions in Iranian fat-tailed sheep.

\section{References}

1. Ayala A, Urbanich MA, Herdon CD, Chaudry IH. Is sepsis induced apoptosis associated with macrophage dysfunction? J Trauma 1996;40:568-73.

2. Andersson U, Wang H, Palmblad K, et al. High mobility group 1 protein (HMG-1) stimulates pro-inflammatory cytokine synthesis in human monocytes. J Exp Med 2000;192:565-70.

3. Jaffer U, Wade RG, Gourlay T. Cytokines in the systemic inflammatory response syndrome: a review. HSR Proc. Intensive Care Cardiovasc Anesth 2010;2:161-75.

4. Radostits OM, Gay CC, Hinchcliff KW, Constable PD. Toxemia and endotoxemia. In: Veterinary Medicine: a text book of the diseases of cattle, horses, sheep, pigs and goats, $10^{\text {th }}$ ed. Philadelphia, USA: Elsevier; 2007. pp 53-60.

5. Chalmeh A, Badiei K, Pourjafar M, Nazifi $\mathrm{S}$. Acute phase response in experimentally Escherichia coli serotype 055:B5 induced endotoxemia and its comparative treatment with dexamethasone and flunixin meglumine in Iranian fat-tailed sheep. Veterinarski Arhiv 2013;83:301-12.

6. Chalmeh A, Badiei K, Pourjafar M, Nazifi S. Anti-inflammatory effects of insulin and dexamethasone on experimentally
Escherichia coli serotype 055:B5 induced endotoxemia in Iranian fat- tailed sheep. $\mathrm{J}$ Fac Vet Med Istanbul Univ 2013;39:197208.

7. Chalmeh A, Badiei K, Pourjafar M, Nazifi S. Anti-inflammatory effects of insulin regular and flunixin meglumine on endotoxemia experimentally induced by Escherichia coli serotype 055:B5 in an ovine model. Inflamm Res 2013;62:61-7.

8. Chalmeh A, Badiei K, Pourjafar M, Nazifi S. Modulation of inflammatory responses following insulin therapy in experimentally bolus intravenous Escherichia coli lipopolysaccharide serotype 055:B5 induced endotoxemia in Iranian fat-tailed sheep. Small Rumin Res 2013;113:283-9.

9. Bertók L. Bile acids in physico-chemical host defence. Pathophysiology 2004;11: 139-45.

10. D’Arcy Hart P. Mycobacterium tuberculosis in macrophages: effect of certain surfactants and other membrane-active compounds. Science 1968;62:686-9.

11. Longworth KE, Smith BL, Staub NC, et al. Use of detergent to prevent initial responses to endotoxin in horses. Am J Vet Res 1996;57:1063-6.

12. Thomassen MJ, Antal JM, Divis LT, Wiedemann HP. Regulation of human alveolar macrophage inflammatory cytokines by tyloxapol: a component of the synthetic surfactant exosurf. Clin Immunol Immunopathol 1995;77:201-5.

13. Ghio AJ, Marshall BC, Diaz JL, et al. Tyloxapol inhibits NF-kappa B and cytokine release, scavenges $\mathrm{HOCI}$, and reduces viscosity of cystic fibrosis sputum. Am J Respir Crit Care Med 1996;154:783-8.

14. Serikov VB, Glazanova TV, Jerome EH, et al. Tyloxapol attenuates the pathologic effects of endotoxin in rabbits and mortality following cecal ligation and puncture in rats by blockade of endotoxin receptor-ligand interactions. Inflammation 2003;27:175-90.

15. Staub NC Sr, Longworth KE, Serikov V, et al. Detergent inhibits 70-90\% of responses to intravenous endotoxin in awake sheep. J Appl Physiol (1985) 2001;90:1788-97.

16. Feldman, B.F., Zinkl, J.G., Jain, N.C. Schalm's Veterinary Hematology, first ed. Lippincott Williams and Wilkins, Philadelphia 2000;891-896.

17. Paglia DE, Valentine WN. Studies on the quantitative and qualitative characteriza- tion of erythrocyte glutathione peroxidase. J Lab Clin Med 1967;70:158-69.

18. Yao YM, Redl H, Bahrami S. The inflammatory basis of trauma/shock-associated multiple organ failure. Inflamm Res1998;47:201-10.

19. Murata H. Stress and acute phase protein response: an inconspicuous but essential linkage. Vet J 2007;173:473-4.

20. Nazifi S, Khoshvaghti A, Gheisari HR. Evaluation of serum and milk amyloid A in some inflammatory diseases of cattle. Iran J Vet Res 2008;9:222-6.

21. Pineiro M, Pineiro C, Carpintero R, et al. Characterization of the pig acute phase protein response to road transport. Vet $\mathrm{J}$ 2007;173:669-74.

22. Gruys E, Obwolo MJ, Toussaint MJM. Diagnostic significance of the major acute phase proteins in veterinary clinical chemistry: a review. Vet Bull 1994;64:1009-18.

23. Skinner JG, Roberts L. Haptoglobin as an indicator of infection in sheep. Vet Rec 1994;134:33-6.

24. Murata H, Shimada N, Yoshioka M. Current research on acute phase proteins in veterinary diagnosis: an overview. Vet $\mathbf{J}$ 2004;168:28-40.

25. Attwood D, Florence TP. Surfactant Systems. London,UK: Chapman \& Hall; 1983.

26. Heinzel FP. The role of IFN- $\gamma$ in the pathology of experimental endotoxemia. J Immunol 1990;145:2920-4.

27. Schroder K, Hertzog PJ, Ravasi T, Hume DA. Interferon-gamma: an overview of signals, mechanisms and functions. J Leukoc Biol 2004;75:163-89.

28. Burchett SK, Weaver WM, Westall JA, et al. Regulation of tumor necrosis factor/cachectin and IL-1 secretion in human mononuclear phagocytes. J Immunol 1998;140:3473-81.

29. Bauer V, Bauer F. Reactive oxygen species as mediators of tissue protection and injury. Gen Physiol Biophys 1999;18:7-14.

30. Pompella A, Visvikis A, Paolicchi A, et al. The changing faces of glutathione, a cellular protagonist. Biochem Pharmacol 2003;66:1499-503.

31. Podil'chalk MD, Vdovychenko VI, Terlets'ka LM. Lipid peroxidation and blood serum peroxidase activity in diseases of the hepatobiliary system. Lik Sprava 1996;1/2:110-2. 